\title{
Increased type 1 chemokine expression in experimental Chagas disease correlates with cardiac pathology in Beagle dogs
}

\author{
Paulo M.M. Guedes ${ }^{\mathrm{a}, *}$, Vanja M. Veloso $^{\mathrm{b}}$, André Talvani ${ }^{\mathrm{b}}$, Livia F. Diniz ${ }^{\mathrm{b}}$, Ivo S. Caldas ${ }^{\mathrm{b}}$, \\ Maria A. Do-Valle-Matta ${ }^{c}$, Juliana Santiago-Silva ${ }^{a}$, Egler Chiari ${ }^{d}$, Lucia M.C. Galvão ${ }^{\text {d,e }}$, \\ João S. Silva ${ }^{a}$, Maria T. Bahia ${ }^{b}$ \\ a Departamento de Bioquímica e Imunologia, Escola de Medicina de Ribeirão Preto/USP, Ribeirão Preto, São Paulo, Brazil \\ b Departamento de Ciências Biológicas/NUPEB, Universidade Federal de Ouro Preto, Ouro Preto, Minas Gerais, Brazil \\ c Laboratório de Ultraestrutura celular, Instituto Oswaldo Cruz/FIOCRUZ, Rio de Janeiro, Brazil \\ d Departamento de Parasitologia, Instituto de Ciências Biológicas, Universidade Federal de Minas Gerais, Belo Horizonte, Minas Gerais, Brazil \\ e Universidade Federal do Rio Grande do Norte Federal, Natal, Rio Grande do Norte, Brazil
}

\section{A R T I C L E I N F O}

\section{Article history:}

Received 21 August 2009

Received in revised form 4 June 2010

Accepted 11 June 2010

\section{Keywords:}

Chemokines

Dog model

Trypanosoma cruzi

Chagas cardiopathy

Inflammation

\begin{abstract}
A B S T R A C T
Chemokines and chemokine receptors interaction have presented important role in leukocyte migration to specific immune reaction sites. Recently, it has been reported that chemokine receptors CXC (CXCR3) and CC (CCR5) were preferentially expressed on Th1 cells while CCR3 and CCR4 were preferentially expressed on Th2 cells. This study evaluated the mRNA expression of type 1 and type 2 chemokine and chemokine receptors in the cardiac tissue of Beagle dogs infected with distinct genetic groups of Trypanosoma cruzi (Y, Berenice78 and $A B C$ strains) during acute and chronic phases. To analyze the correlation between chemokine and chemokine receptors expression and the development of heart pathology, the chronic infected animals were divided into groups, according to the parasite strain and based on the degree of heart damage: cardiac and indeterminate form of Chagas disease. Our results indicated that cardiac type $1 / 2$ chemokines and their receptors were partially dependent on the genetic diversity of parasites as well as the polarization of clinical forms. Also, dogs presenting cardiac form showed lower heart tissue mRNA expression of CCL24 (type 2) and higher expression of CCL5, CCL4 and CXCR3 (type 1) when compared with those with indeterminate form of disease. Together, these data reinforce a close-relation between T. cruzi genetic population and the host specific type 1 immune response and, for the first time, we show the distribution of type $1 / 2$ chemokines associated with the development of cardiac pathology using dogs, a well similar model to study human Chagas disease.
\end{abstract}

(C) 2010 Elsevier B.V. All rights reserved.

\footnotetext{
* Corresponding author at: Departamento de Bioquímica e Imunologia, Faculdade de Medicina de Ribeirão Preto, Av. dos Bandeirantes 3900, Monte Alegre, 14049-900, Ribeirão Preto, SP, Brazil. Tel.: +55 163602 3234; fax: +55 1636024590 .

E-mail addresses: pauloguedes@usp.br, pauloguedes@cb.ufrn.br (P.M.M. Guedes)
}

\section{Introduction}

Chagas disease is a neglected illness caused by the intracellular parasite Trypanosoma cruzi, which is transmitted by hematophagous reduviid vectors. Although it has been described 100 years ago by Carlos Chagas, this disease still represents an important health problem, being broadly dispersed in 18 developing countries in South and Central Americas. Its main clinical manifestations are cardiac and/or digestive disturbances, with an overall prevalence of 
about 12-14 million cases, been considered a major cause of cardiac infection disease in endemic areas (WHO, 2005). It is estimated that $10-30 \%$ of $T$. cruzi-infected individuals will progress to chronic irreversible cardiac pathology, causing considerable morbidity and mortality. Chagas cardiopathy (CC) is characterized by myocarditis, in which an important lymphomononuclear infiltrate is accompanied by interstitial fibrosis and cardiomyocyte hypertrophy that can lead to dilated cardiomyopathy, end-stage heart failure, and death. Inflammatory infiltrates are composed primarily of $\mathrm{CD}^{+} \mathrm{T}$ cells but also contain $\mathrm{CD} 4^{+} \mathrm{T}$ cells and macrophages (Higuchi, 1997).

Although it is widely accepted that inflammatory infiltrate is the ultimate effector of myocardial damage, the exact mechanism through which only a subset of infected individuals develop CC remains poorly understood (Higuchi, 1997). The cytokine profile has been pointed as essential key to orchestrate the immune response against $T$. cruzi and define immunopathological mechanisms involved in CC. It was previously described, for instead, that individuals with CC are high producers of IFN-gamma, TNF- $\alpha$ and IL-6, and less producers of IL-4 and IL-10 evaluated in peripheral blood lymphocytes and heart tissue mononuclear cells, when compared to those asymptomatic (Abel et al., 2001; Gomes et al., 2003). Proinflammatory cytokines (e.g. IFNgamma) appear to mediate, directly and indirectly, the synthesis or expression of chemokines, essential elements to the inflammatory and immune-mediated Chagas disease process in the cardiac tissue (Talvani et al., 2000).

Chemokines and their cognate receptors drive leukocytes and monocytes recruitment from the bloodstream into inflamed tissues and are important immunological markers of profiles Th1 (CCL2, CCL3, CCL4, CCL5, CXCL9, CXCL10, CXCL11, CCR5 and CXCR3), Th2 (CCL1, CCL11, CCL17, CCL22, CCL24, CCL26, CCR3, CCR4 and CCR8), Th17 (CCL17, CCL20, CCL22, CCR4 and CCR6), and regulatory T cells (CCL1, CCL17, CCL22, CCR4 and CCR8) (Bromley et al., 2008). However, several disease and parasite models showed different pattern of chemokine expression in the Th1, Th2, Th17 and regulatory T cell (Bromley et al., 2008). In the context of human Chagas disease, soluble chemokines were previously associated with high serum TNF- $\alpha$ and correlated with worst prognosis in individuals with CC (Talvani et al., 2004). In parallel, peripheral mononuclear cells from CC individuals showed higher coexpression of CCR5 or CXCR3 and IFN- $\gamma$ than patients presenting the indeterminate form of disease, suggesting that chemokines and their receptors are strongly involved in the development of the early forms of CC (Gomes et al., 2005; Talvani et al., 2004).

Another aspect emerged in the last decade concerning pathogenesis of Chagas disease was the participation of genetic diversity of $T$. cruzi in coordinate host immune response and define cardiac clinical disturbances. We have recently contributed to this understand showing that different strains of the parasite present distinct patterns of virulence, immune response and the pathogenesis during experimental Chagas disease (Guedes et al., 2008, Santos et al., 2009).
A major stumbling block for research efforts striving to elucidate the mechanisms of pathogenesis of human chronic Chagas disease are the lack of a suitable animal model. Our group has shown that dogs develop diffuse chronic myocarditis with alterations in immune, pathological, electro- and echocardiography similar to those described in humans (Lana and Chiari, 1986; Guedes et al., 2007, 2008). In fact, we have previously showed, in the same animals used in this study, that those with indeterminate clinical form were associated with high IL-10 production during the acute phase of the disease, while those with cardiac form were associated with high IFN- $\gamma$, TNF- $\alpha$ and low or nil IL-10 production (Guedes et al., 2009). The propose of this study is investigate the expression of Th1, Th2, Th17 profiles of chemokines and their receptors in heart tissue from Beagle dogs and verify whether different populations of $T$. cruzi (Berenice-78, Y and ABC strains) can interfere in this chemokine background and in the cardiac pathology during acute and chronic phases of Chagas disease.

\section{Materials and methods}

\subsection{Trypanosoma cruzi stocks}

Three distinct strains of $T$. cruzi II stocks were used in this proposal according their virulence pattern and capacity to induce pathogenesis in dog model: Y, Berenice-78 and $A B C$ strains of the parasite, as previously described by Guedes et al. (2007).

\subsection{Experimental animals and infection}

Four-month old Beagle dogs $(n=32)$ from the kennels at the Universidade Federal de Ouro Preto (UFOP) were used in this study. All procedures and experimental protocols were conducted in accordance with the procedures issued by the Brazilian College of Animal Experimentation (COBEA) and approved by the Ethics Committee in Animal Research at UFOP. Animals were fed with commercial dog food and water ad libitum. Prior to the study, pups were dewormed and vaccinated with Vanguard ${ }^{\circledR}$ HTLP 5/CV-L (Pfizer). Twenty-four Beagle dogs were inoculated with $4.0 \times 10^{3}$ bloodstream trypomastigotes per $\mathrm{kg}$ of body weight of the Y, Berenice-78 (Be-78) and $A B C$ T. cruzi strains and euthanised 4 (acute phase) and 100 (chronic phase) weeks after infection. Eight age-matched non-infected dogs were used as controls. Latter, to analyze the correlation between chemokine and chemokine receptors expression and the development of heart pathology, dogs were divided into groups, during chronic phase, according to the degree of heart damage: (i) cardiac form - defined by the presence of cardiomegaly, inflammation and fibrosis in the heart tissue; (ii) indeterminate form defined by the absence of pathological signals.

\subsection{Total RNA isolation and $c D N A$ synthesis from the canine heart tissue}

Total RNA from cardiac tissues (30-35 mg of left ventricle) were isolated using $0.5 \mathrm{~mL}$ of TRIZOL reagent 
(Invitrogen) and SV Total RNA Isolation System (Promega, Madson, WI) according to manufacturer instructions. The RNA yield and the ratio of absorbance at $260-280 \mathrm{~nm}$ $\left(A_{260} / A_{280}\right.$ ratio) were measured using the NanoVue PLus Spectrophotometer (GE Healthcare, UK). Samples containing $<10 \mathrm{ng} / \mu \mathrm{L}$ of RNA were excluded from the study. The cDNA was synthesized using $1 \mu \mathrm{g}$ of tRNA through a reverse transcription reaction (ImProm-II ${ }^{\mathrm{TM}}$ Reverse Transcriptase, Promega). The cDNA $\beta$-actin copy number/RNA $\beta$-actin copy number ratio was calculated as a measure of the efficiency of the cDNA synthesis; this ratio was used to normalize the reference gene copy numbers as assessed by quantitative real-time PCR.

\subsection{Development of real-time PCR assays for canine chemokine and chemokine receptors}

For all chemokine and chemokine receptors genes, a standard curve from serial dilutions of a known concentration of purified DNA was achieved. This quantified DNA consisted of the target PCR product prepared by conventional PCR from cDNA positive for the corresponding target mRNA. Threefold measurement for each standard dilution point over the whole standard curve range was produced to generate a reliable standard curve.

Then, real-time PCR quantitative mRNA analyses were performed in an ABI Prism 7000 SDS (Applied Biosystems) using the Platinum ${ }^{\circledR}$ SYBR $^{\circledR}$ Green qPCR SuperMix UDG with ROX reagent (Invitrogen) for quantification of amplicons. The standard PCR conditions were as follows: $50^{\circ} \mathrm{C}(2 \mathrm{~min}), 95^{\circ} \mathrm{C}(10 \mathrm{~min}) ; 40$ cycles of $94^{\circ} \mathrm{C}(30 \mathrm{~s})$, $58^{\circ} \mathrm{C}(30 \mathrm{~s})$, and $72^{\circ} \mathrm{C}(1 \mathrm{~min})$; followed by the standard denaturation curve. The sequences of dog primers were designed using the Primer Express software (Applied Biosystems) using nucleotide sequences present in the GenBank database (Table 1). In each reaction the Platinum ${ }^{\circledR}$ SYBR $^{\circledR}$ Green qPCR SuperMix UDG with ROX reagent (Invitrogen), $1 \mu \mathrm{g} / \mu \mathrm{L}$ of each specific primer, and cDNA diluted 20 times were used. In all this study, data were normalized to $\beta$-actin mRNA. Relative increase in chemokines and their receptors were plotted in comparison to non-infected dogs control group (calibrator of the reaction) using $2^{-\Delta \Delta C T}$ method, as previously described (Livak and Schmittgen, 2001).

\subsection{Statistical analysis}

Data are expressed as the mean \pm standard error of the mean (SEM) and analyzed using one-way analysis of variance. All analyses were performed using the PRISM 3.0 software 292 (GraphPad, San Diego, CA, USA) and the level of significance was accepted at $p<0.05$.

\section{Results and discussion}

The results of this study show that dogs with cardiac form of Chagas disease presented lower mRNA expression of CCL24 (type 2) and higher expression of CCL5, CCL4 and CXCR3 (type 1) than those presenting indeterminate form of the disease. These findings suggest that the immunological imbalance observed in the cardiac animals may

\section{Table 1}

The sequences of the primers were designed based on nucleotide sequences in the GenBank Database and were used were as follows.

\begin{tabular}{|c|c|}
\hline Target & Sense and antisense sequences \\
\hline CCL1 & $\begin{array}{l}\text { ACTTTTCAGAGAAGAGGATCGC } \\
\text { TGGAGCTGGTGTGTTTGTAACA }\end{array}$ \\
\hline CCL2 & $\begin{array}{l}\text { TAAAAGAGTCACCAGCAGCAA } \\
\text { TTTAGGACGGTCTTGAAGATCA }\end{array}$ \\
\hline CCL3 & $\begin{array}{l}\text { CAAGCAGATTCCACGCAAGTT } \\
\text { TAATACCGGGCTTGGAGCAT }\end{array}$ \\
\hline CCL4 & $\begin{array}{l}\text { TGACCGTCCTTTCTCTCCTT } \\
\text { GATCTGAACCCATTGGTGCT }\end{array}$ \\
\hline CCL5 & $\begin{array}{l}\text { AAGGGCTGACTGATAAATGTGA } \\
\text { AGCGAGAATTTTAATGGAAAGC }\end{array}$ \\
\hline CCL17 & $\begin{array}{l}\text { CCATCGTGTTTGTAACTGTCCA } \\
\text { AATATCTGACCGCCTTCTTCAC }\end{array}$ \\
\hline CCL20 & $\begin{array}{l}\text { TATGGTTCCTCCCGGATCTATC } \\
\text { TCATTGGCCAGCTGTTGTGT }\end{array}$ \\
\hline CCL24 & $\begin{array}{l}\text { CCTGCTGCATGTTCTTCATTTC } \\
\text { TTCTGGTTCTTCTTGGTGGTGA }\end{array}$ \\
\hline CCL26 & $\begin{array}{l}\text { TCTTCATCCTGAGTGTCCATCG } \\
\text { AGCAGAACTTGGCCACATCA }\end{array}$ \\
\hline CXCL9 & $\begin{array}{l}\text { CAGATGGTCCTTAAGCCACTTT } \\
\text { CCTTTCCCTGTGAACCTCAA }\end{array}$ \\
\hline CXCL10 & $\begin{array}{l}\text { CACATGTTGAGATCATTGCCAC } \\
\text { TTCAGACATCTTTTCTCCCCA }\end{array}$ \\
\hline CCR3 & $\begin{array}{l}\text { CTAGCAGCCTCCCCTGAATTTA } \\
\text { TGTTCAGACTCCTTTTGGGACT }\end{array}$ \\
\hline CCR4 & $\begin{array}{l}\text { TTTGGACTAGGTCTCTGCAAGA } \\
\text { AAAAGCCCACCAGGTACATC }\end{array}$ \\
\hline CCR5 & $\begin{array}{l}\text { TGTGTCTGCTTCAAAAGCCC } \\
\text { TCACTTGTCACCACCCCAAA }\end{array}$ \\
\hline CCR6 & $\begin{array}{l}\text { AGCTGTTTGTGCCAATTGCTTA } \\
\text { AAAATATTGCCCAGGAGGCC }\end{array}$ \\
\hline CCR8 & $\begin{array}{l}\text { TGATATCATCTCAAGCCCCTG } \\
\text { AGCAACTTGCTGTCTCTTTGGA }\end{array}$ \\
\hline CXCR3 & $\begin{array}{l}\text { TTCTTTGCCATCCCAGATTTC } \\
\text { ATGCATGGCATTTAGGCG }\end{array}$ \\
\hline$\beta$-actin & $\begin{array}{l}\text { CCACTTTCCTGTCTTACCCAA } \\
\text { AATTAACCACCCACGGTGTT }\end{array}$ \\
\hline
\end{tabular}

be correlated to deficient type 2 chemokine expression and consequently deficient in Th2 cells migration to the heart.

The prototypical chemokines response in vitro is chemotactic migration to leukocytes. The expression of CXCL9 and CCL1 during acute phase and CCL5 during chronic phase of $T$. cruzi infection, involved in T cell migration to the heart tissue of infected Beagle dogs, was increased in the heart tissue of $\mathrm{Y}$ - and $\mathrm{ABC}$-infected dogs when compared to Be-78-infected animals (Fig. 1A). These animals showed a more intense myocarditis and fibrosis than those Be78-infected dogs (Guedes et al., 2009). Our results with CXCL9/MIG and CCL5/RANTES in dogs are in according with one previously study using the clonotype I Colombian strain of the parasite. In this study, authors also shown the abundance of CXCL9, CCL5 and CXCL10 chemokines in the cardiac tissue of mice in the acute and chronic phases 

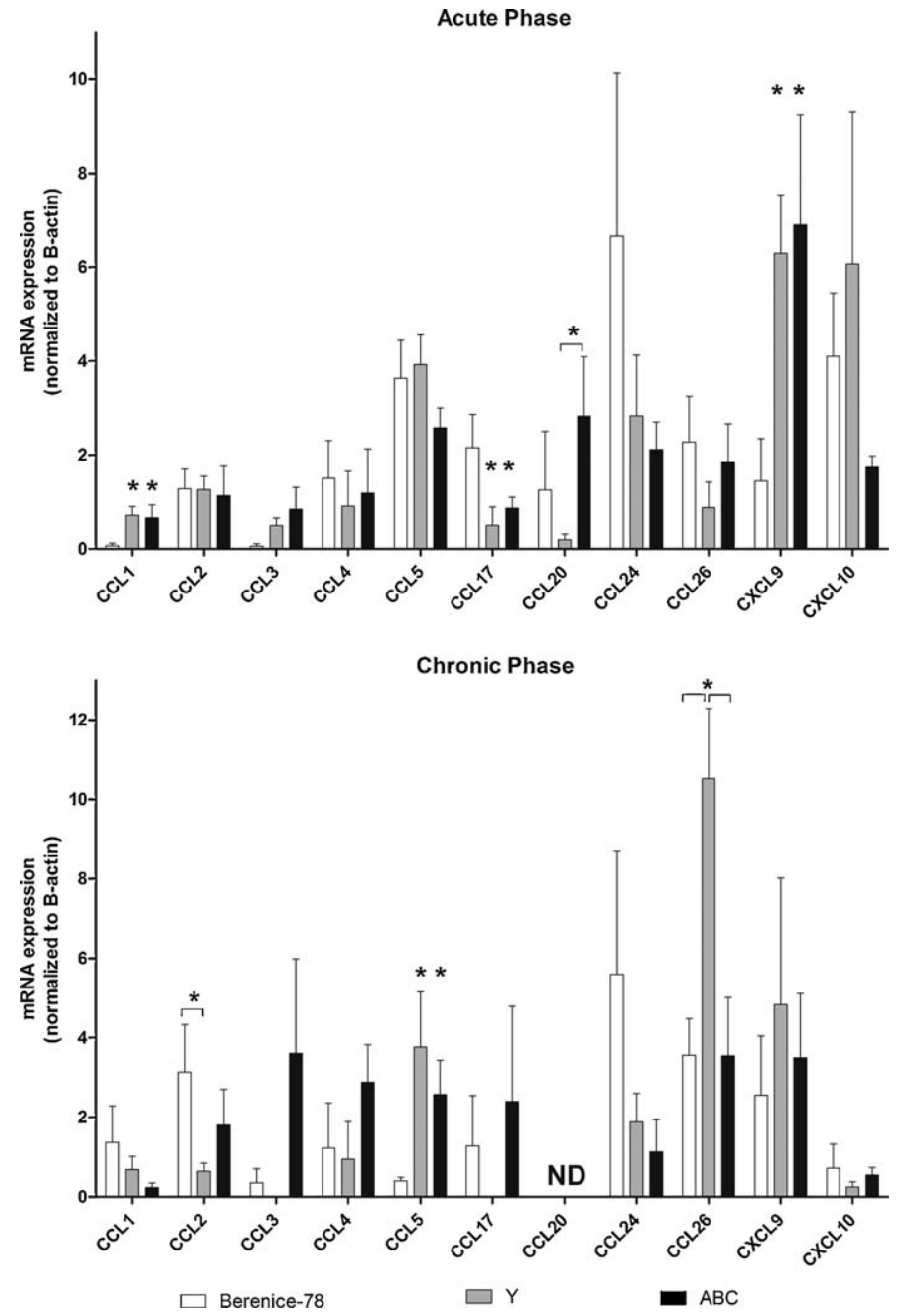

Fig. 1. Expression of type 1 and type 2 chemokines in heart from infected dogs, under influence of different populations of Trypanosoma cruzi, during acute and chronic phases. Beagle dogs were infected with Berenice-78, Y and ABC strains of $T$. cruzi and mRNA expression of chemokines determined in heart tissue in the acute (A) and chronic (B) phases of the disease. After normalization to $\beta$-actin mRNA, relative increase of type 1 and type 2 chemokines was plotted in comparison to non-infected animals (control group) and data presented using $2^{-\Delta \Delta \mathrm{CT}}$ method. Data (mean \pm SEM) are representative of four dogs per group. ${ }^{*} P<0.05$. ND: not detected.

of infection (Petray et al., 2002). In fact, our data with the canine model showed (i) Y and ABC strains inducing a more intense myocarditis and fibrosis as compared to Be-78infected dogs (Guedes et al., 2009), and complementary, (ii) an increased mRNA level for CXCL9 during acute phase and CCL5 during chronic phase in heart tissue of animals infected with high pathogenic $Y$ and $A B C$ strains. In addition, an important cellular migration to the heart tissue was observed with an overexpression of these chemokines and, accordingly, high tissue lesion.

The CCL20 expression during acute phase was higher in the heart of dogs infected with $A B C$ than $Y$ strain, and CCL2 mRNA expression was higher in Be-78-than Y-infected animals during the chronic phase (Fig. 1B). A defective expression of this last chemokine, named monocyte chemoattractant protein/MCP-1, leads to major phenotypes of a defective monocyte trafficking in mice with no $T$. cruzi infection, creating a Th1/Th2 balance (Murphy et al., 2000). Here, we did not observe differences among other chemokine expression in the heart of dogs infected with distinct $T$. cruzi strains. In vitro studies using murine inflammatory macrophages (Aliberti et al., 1999) showed that CCL2/MCP-1 signaling both increased the macrophage uptake of $T$. cruzi and enhanced the production of NO, with consequential parasite killing, a fact that implicates CCL2 in the control of parasite growth. Indeed, chemokines have been considered as key factors in numerous biological processes, including those involving host-parasite interactions. Myocardial CCL2 expression in response to tissue invasion by $T$. cruzi was previously demonstrated, suggesting that it plays an important role in the CCL2:CCR2 signaling axis, thereby promoting host defense (Talvani et al., 2000). Our results in the canine model contribute with former reports, by comparing the 

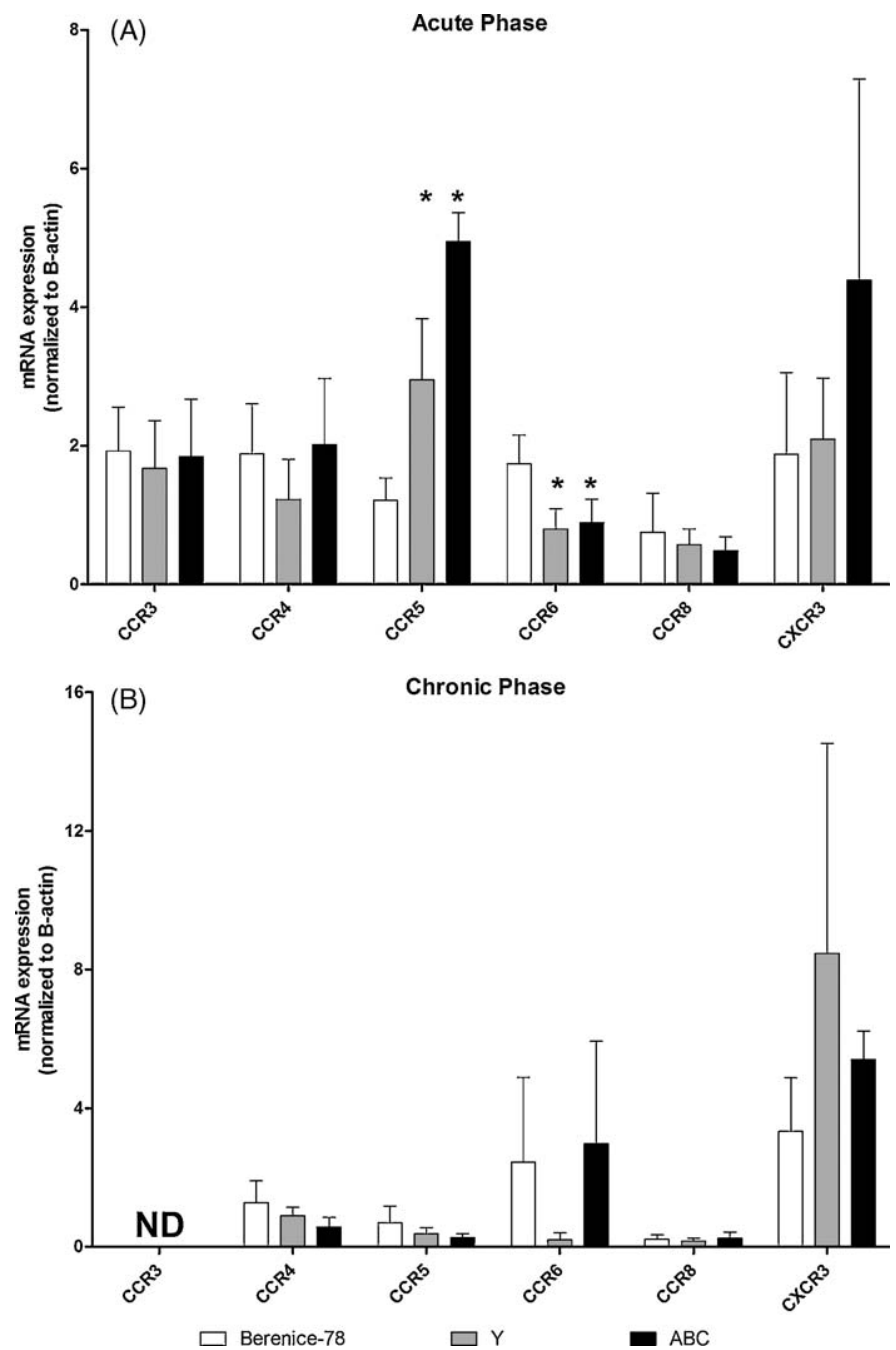

Fig. 2. Expression of type 1 and type 2 chemokine receptors in heart from infected dogs, under influence of different populations of Trypanosoma cruzi, during acute and chronic phase. Beagle dogs were infected with Berenice-78, Y and ABC strains of T. cruzi and mRNA expression of chemokines determined in heart tissue during acute (A) and chronic (B) phases of the disease. After normalization to $\beta$-actin mRNA, relative increase of type 1 and type 2 chemokine receptors was plotted in comparison to non-infected animals (control group) and data presented using $2^{-\Delta \Delta \mathrm{CT}}$ method. Data (mean $\pm \mathrm{SEM}$ ) are representative of four dogs per group. ${ }^{*} P<0.05$. ND: not detected.

strains which can cause more severe $(\mathrm{Y}, \mathrm{ABC})$ or milder (Be-78) disease. This last strain bearing the character of a better prognosis, showed a significantly higher level of CCL2 chemokine in the chronic phase when compared to both strains with somber prognosis. Indeed, the unique infective strain, used in our comparative study, which allowed animals (50\%) progress into the indeterminate form of the chronic phase of Chagas disease was Be-78 strain. This result suggests the existence of a role for CCL2 in alleviating the deleterious effects of cellular migration to heart tissue by reducing parasite burden consequent to $T$. cruzi invasion. The expression of CCR5, a chemokine receptor expressed in activated $\mathrm{T}$ cell, macrophage and NK cells, and important for the development of myocarditis during experimental T. cruzi infection (Machado et al., 2005), was increased in the heart tissue of the acute phase of $\mathrm{Y}$ and $\mathrm{ABC}$-infected dogs when compared to Be-78infected animals (Fig. 2A). Our previous works (Guedes et al., 2009, 2007) demonstrated that $Y$ and $A B C$ strains are more pathogenic for dogs than Be-78, which induced a less severe cardiac damage to the infected animals. Indeed, during the chronic phase of infection two cardiac fibrosis patterns were observed in the right atrial wall of dogs: animals infected with $Y$ and $A B C$ strains showed severe intra-fascicular collagen deposition, while dogs infected with the Be-78 strain presented discreet fibrosis (Guedes et al., 2009). Marino and colleagues (Marino et al., 2004) using $\mathrm{C} 3 \mathrm{H} / \mathrm{HeJ}$ model of infection, demonstrated that $\mathrm{CD} 8^{+} \mathrm{T}$ cells expressing CCR5 were prevalent in the heart inflammatory infiltrates. In this study, the administration of Met-RANTES, a CR1/CCR5 antagonist, to T. cruzi-infected mice induced increased survival rates, associated with: a decreased of 
intracardiac $\mathrm{CD}^{+}$and $\mathrm{CD}^{+} \mathrm{T}$ cells influx, a diminished deposition of fibronectin in heart tissues and an attenuated myocarditis. Latter, another group demonstrated that CCR5 expression on $\mathrm{CD}^{+} \mathrm{T}$ cells was positively modulated during experimental Chagas disease (Machado et al., 2005). Accordingly, mRNA and protein for the CCR5 ligands CCL3, CCL4 and CCL5 were associated with $\mathrm{CD} 4^{+}$and $\mathrm{CD} 8^{+} \mathrm{T}$ cells in the heart of infected mice. Furthermore, CCR5-deficient C57Bl/6 mice showed impairment in T cell migration to the heart, being susceptible to acute infection and confirming an essential role for CCR5 and its ligands in the control of T cell influx in infected C57Bl/6 mice. Considering the bulk of information on the deleterious role of CCR5 on the heart Chagas disease, and looking at the comparative results concerning different populations of $T$. cruzi, we may suggest a pivotal role to CCR5 acting on the enhancement of inflammatory cardiac remodeling in CC, according our previously data with Y- and ABC-infected animals (Guedes et al., 2009).

The expression of CCR6, a chemokine receptor expressed in Th17 and regulatory $\mathrm{T}$ cells (Bromley et al., 2008), was markedly reduced in the heart tissue of $\mathrm{Y}$ and $\mathrm{ABC} T$. cruzi-infected dogs during acute phase of infection (Fig. 2A). Interaction between CCL20 and CCR6 is responsible for chemoattraction of immature dendritic cells, effector and memory T cells, and B cells to inflammatory sites (Bromley et al., 2008). These data support our theory about a poor CCR6 expression associated with $\mathrm{ABC}$ and $\mathrm{Y}$ strains during acute phase of infection (Fig. 2A) which could argue about the role of Th17 delineating the events of the chronic phase. In this delayed phase, the expression of CCR3, CCR4, CCR8 and CXCR3 in the heart was similar among groups of dogs infected with $\mathrm{Y}, \mathrm{ABC}$ and Be-78 strain, while CCR3 mRNA expression was not
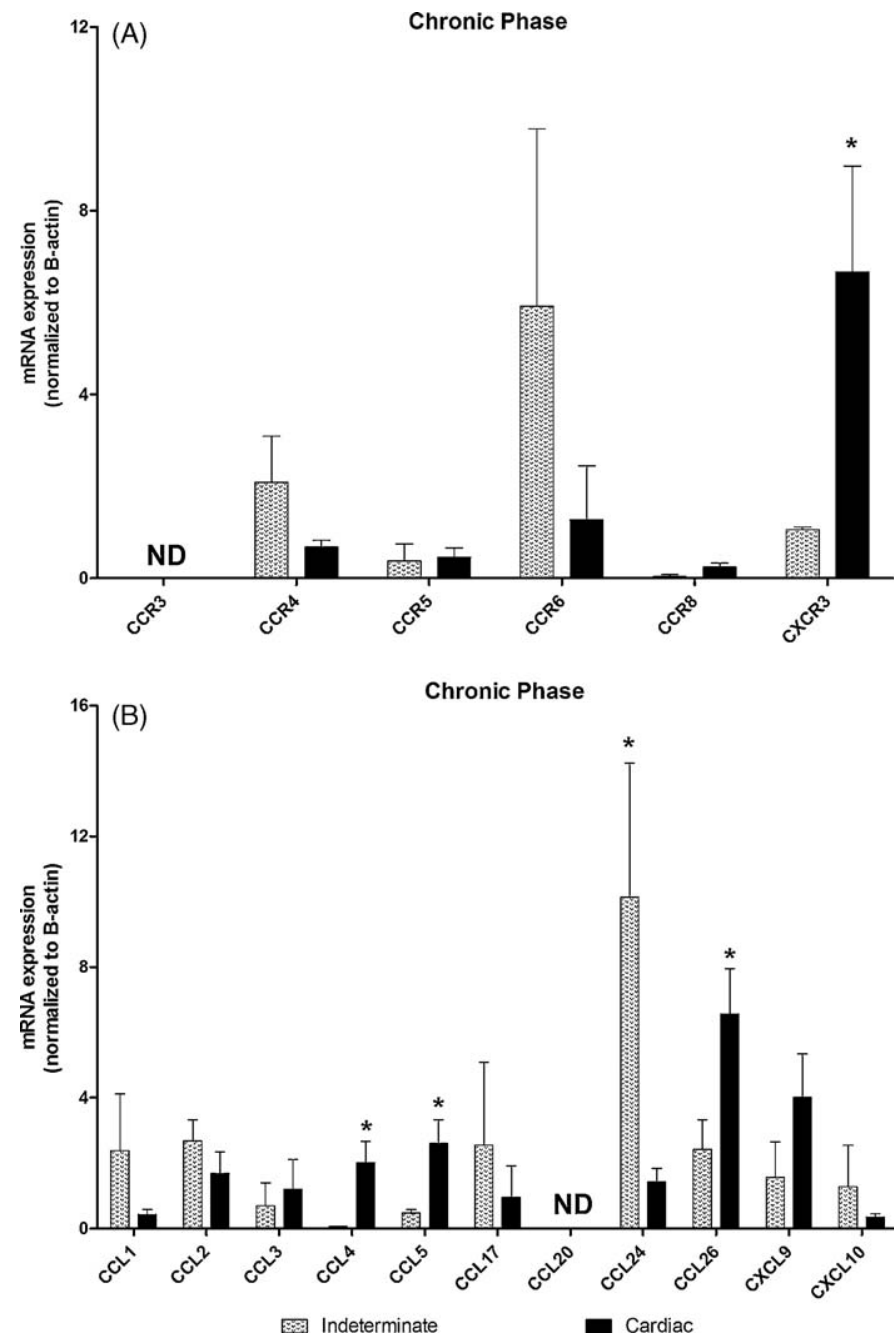

Fig. 3. Expression of chemokine receptors in cardiac tissue from dogs presenting indeterminate and cardiac polar forms of the chronic Chagas disease. Infected Beagle dogs were divided into two groups, according their clinical manifestations (indeterminate and cardiac). Then, they were euthanised during chronic phase and mRNA expression of type 1 and type 2 chemokine receptors (A) and chemokines (B) determined in heart tissue. Data (mean \pm SEM) are representative of at least 10 dogs per group and data were shown using $2^{-\Delta \Delta C T}$ method. ${ }^{*} P<0.05$. ND: not detected. 
detected (Fig. 2B). Chemokines are well-described agents in the mechanism leading to myocarditis during experimental T. cruzi infection (Talvani et al., 2000; Machado et al., 2005). In this study, the increase of CCR5 mRNA expression may be correlated to high myocarditis while CCR6 expression with the balance of inflammatory response in those animals infected with $\mathrm{Y}$ and $\mathrm{ABC}$ strains during acute phase (Fig. 2A). In accordance with this hypothesis, we observed, in mice infected with $T$. cruzi, that IL-17 production was essential to control T. cruzi-induced myocarditis at same time that modulated chemokines and IFN-gamma production (Guedes et al., 2010).

Here, dogs infected with $\mathrm{Y}$ and $\mathrm{ABC}$ strains, and $50 \%$ of those infected with the Be-78 strain presented $\mathrm{CC}$, while $50 \%$ of the animals infected with the Be-78 presented indeterminate form (Guedes et al., 2009). The profile of chemokine receptor expression differed strongly between cardiac and indeterminate groups and reflected an imbalance toward a type 1 response in the cardiac group of dogs. The expression of CCL4, CCL5, CCL26 and CXCR3 mRNA in the heart was higher in animals presenting CC cardiac form of disease; on the other hand, animals categorized in indeterminate group showed higher expression of CCL24 than those with CC (Fig. 3A and B). CCL24/eotaxin-2 was highly expressed associated with chronic indeterminate form after infection with Be-78 strain of $T$. cruzi. This finding reinforces the existence of a fine tuning among chemokine receptors which can mediate the selective recruitment of effectors type- 1 or -2 cells into tissues depending on the pathogen and on the host immune response (Bromley et al., 2008). In general, kinetic for expression of type1 chemokine/chemokine receptors mRNA was coincident to the intensity of myocarditis in the animals infected with $T$. cruzi. Of note, studies on the co-expression of chemokine receptors of type-1 (CCR5 and CXCR3) and type-2 (CCR3) on $\mathrm{CD}^{+}$and $\mathrm{CD}^{+} \mathrm{T}$ cells producing type1 or type- 2 cytokines from chagasic patients revealed a high percentage of single positive cells co-expressing CCR5 and IFN-gamma, CCR3 and IFN-gamma, and TNFalpha in patients with cardiopathy in comparison with indeterminate clinical form. By contrast, the proportions of $\mathrm{CD}^{+}$or $\mathrm{CD}^{+} \mathrm{T}$ cells co-expressing CCR3 plus IL-10 were lower in the indeterminate group (Gomes et al., 2005; Talvani et al., 2004). Noteworthy, our results in the canine model are consistent with those former reported with chagasic patients. Cardiac group registered high levels of CXCR3 receptor (Fig. 3A), IFN-gamma and TNF-alpha levels when compared to animals included in the indeterminate group, whose predominant cytokine was IL-10 (Guedes et al., 2009). In this vein, the progressive destructive process in cardiac group could, therefore, result from a pathogenic Th1 response which is down regulated by IL-10 (Gomes et al., 2005).

The findings here reported suggest that the development of the chronic cardiac form of the disease during experimental T. cruzi infection in dogs is related to a strong chemokines induced-Th1 cells migration to the heart during the acute and chronic phase of the disease, while the development of the indeterminate form results from a blend of Th1, Th2, Th17 and regulatory T cells chemokines and chemokine receptors expression in the heart. Col- lectively our data in the canine model shed light on the intricate web of cytokine-chemokine-mediated circuits in that they contribute to accumulate evidences on the involvement of specific cytokines in the effective progression through a mild/severe Chagas disease prognosis.

\section{References}

Abel, L.C., Rizzo, L.V., Ianni, B., Albuquerque, F., Bacal, F., Carrara, D., Bocchi, E.A., Teixeira, H.C., Mady, C., Kalil, J., Cunha-Neto, E., 2001. Chronic Chagas' disease cardiomyopathy patients display an increased IFN-gamma response to Trypanosoma cruzi infection. Journal of Autoimmunity 17, 99-107.

Aliberti, J.C., Machado, F.S., Souto, J.T., Campanelli, A.P., Teixeira, M.M., Gazzinelli, R.T., Silva, J.S., 1999. beta-Chemokines enhance parasite uptake and promote nitric oxide-dependent microbiostatic activity in murine inflammatory macrophages infected with Trypanosoma cruzi. Infection and Immunity 67, 4819-4826.

Bromley, S.K., Mempel, T.R., Luster, A.D., 2008. Orchestrating the orchestrators: chemokines in control of T cell traffic. Nature Immunology 9 , 970-980.

Gomes, J.A., Bahia-Oliveira, L.M., Rocha, M.O., Busek, S.C., Teixeira, M.M., Silva, J.S., Correa-Oliveira, R., 2005. Type 1 chemokine receptor expression in Chagas' disease correlates with morbidity in cardiac patients. Infection and Immunity 73, 7960-7966.

Gomes, J.A., Bahia-Oliveira, L.M., Rocha, M.O., Martins-Filho, O.A., Gazzinelli, G., Correa-Oliveira, R., 2003. Evidence that development of severe cardiomyopathy in human Chagas' disease is due to a Th1-specific immune response. Infection and Immunity 71 , 1185-1193.

Guedes, P.M., Veloso, V.M., Afonso, L.C., Caliari, M.V., Carneiro, C.M., Diniz, L.F., Marques-da-Silva, E.A., Caldas, I.S., Do Valle Matta, M.A., Souza, S.M., Lana, M., Chiari, E., Galvao, L.M., Bahia, M.T., 2009. Development of chronic cardiomyopathy in canine Chagas disease correlates with high IFN-gamma, TNF-alpha, and low IL-10 production during the acute infection phase. Veterinary Immunology and Immunopathology 130, 43-52.

Guedes, P.M., Veloso, V.M., Caliari, M.V., Carneiro, C.M., Souza, S.M., de Lana, M., Chiari, E., Bahia, M.T., Galvao, L.M., 2007. Trypanosoma cruzi high infectivity in vitro is related to cardiac lesions during long-term infection in Beagle dogs. Memorias do Instituto Oswaldo Cruz 102, $141-147$.

Guedes, P.M., Veloso, V.M., Gollob, K.J., Afonso, L.C., Caldas, I.S., Vianna, P., de Lana, M., Chiari, E., Bahia, M.T., Galvao, L.M., 2008. IgG isotype profile is correlated with cardiomegaly in Beagle dogs infected with distinct Trypanosoma cruzi strains. Veterinary Immunology and Immunopathology 124, 163-168.

Guedes, P.M., Gutierrez, F.R., Maia, F.L., Milanezi, C.M., Silva, G.K., Pavanelli, W.R., Silva, J.S., 2010. IL-17 produced during Trypanosoma cruzi infection plays a central role in regulating parasite-induced myocarditis. PloS Neglected Tropical Disease 4, e604.

Higuchi, M.L., 1997. Chronic chagasic cardiopathy: the product of a turbulent host-parasite relationship. Revista do Instituto de Medicina Tropical de Sao Paulo, 53-60.

Lana, M., Chiari, C.A., 1986. Comparative biological characterization of Berenice and Berenice-78 strains of Trypanosoma cruzi isolated from the same patient at different times. Memorias do Instituto Oswaldo Cruz, 247-253.

Livak, K.J., Schmittgen, T.D., 2001. Analysis of relative gene expression data using real-time quantitative PCR and the $2^{-\Delta \Delta C T}$ method. Methods 25 , 402-408.

Machado, F.S., Koyama, N.S., Carregaro, V., Ferreira, B.R., Milanezi, C.M., Teixeira, M.M., Rossi, M.A., Silva, J.S., 2005. The Journal of Infectious Diseases 191, 627-636.

Marino, A.P., da Silva, A., dos Santos, P., Pinto, L.M., Gazzinelli, R.T., Teixeira, M.M., Lannes-Vieira, J., 2004. Regulated on activation, normal T cell expressed and secreted (RANTES) antagonist (Met-RANTES) controls the early phase of Trypanosoma cruzi-elicited myocarditis. Circulation 110, 1443-1449.

Murphy, A., Long, A., Volkov, Y., Kelleher, D., 2000. Cross-linking of LFA-1 induces secretion of macrophage inflammatory protein (MIP)-I alpha and MIP-1beta with consequent directed migration of activated lymphocytes. European Journal of Immunology 30, 3006-3011.

Petray, P., Corral, R., Meckert, P., Laguens, R., 2002. Role of macrophage inflammatory protein-1alpha (MIP-1alpha) in macrophage homing in the spleen and heart pathology during exper- 
imental infection with Trypanosoma cruzi. Acta Tropica 83, 205-211.

Santos, D.M., Talvani, A., Guedes, P.M., Machado-Coelho, G.L., de Lana, M., Bahia, M.T., 2009. Trypanosoma cruzi: genetic diversity influences the profile of immunoglobulins during experimental infection. Experimental Parasitology 121, 8-14.

Talvani, A., Ribeiro, C.S., Aliberti, J.C., Michailowsky, V., Santos, P.V., Murta, S.M., Romanha, A.J., Almeida, I.C., Farber, J., Lannes-Vieira, J., Silva, J.S., Gazzinelli, R.T., 2000. Kinetics of cytokine gene expression in experimental chagasic cardiomyopathy: tissue parasitism and endogenous IFN-gamma as important determinants of chemokine mRNA expres- sion during infection with Trypanosoma cruzi. Microbes and Infection 2, 851-866.

Talvani, A., Rocha, M.O., Ribeiro, A.L., Correa-Oliveira, R., Teixeira, M.M., 2004. Chemokine receptor expression on the surface of peripheral blood mononuclear cells in Chagas disease. The Journal of Infectious Diseases 189, 214-220.

WHO, 2005. Tropical Disease Research: Progress 2003-2004 Seventeenth Programme Report of the UNICEF/UNDP/World Bank/WHO. Special Programme for Research \& Training in Tropical Diseases (TDR). World Health Organization, Geneva, pp. 31-33. 